\title{
Nomes para a "calçada" no Centro-Oeste do Brasil: um estudo geolinguístico
}

\author{
Luciene Gomes Freitas Marins \\ Universidade Federal do Mato Grosso do Sul (UFMS), \\ Campo Grande, Mato Grosso do Sul, Brasil \\ lucienefreitasmarins@gmail.com
}

DOI: http://dx.doi.org/10.21165/el.v46i1.1705

\begin{abstract}
Resumo
Este trabalho analisa aspectos relacionados à interpenetração do falar rural e urbano na norma lexical de habitantes da Região Centro-Oeste, buscando identificar interferências de aspectos extralinguísticos e espaciais na forma de nomear um mesmo elemento da realidade. Foram analisados seis itens lexicais fornecidos como respostas para o seguinte conceito: "na cidade, os automóveis andam no meio da rua e as pessoas nos dois lados, num caminho revestido de lajes ou ladrilhos. Como se chama este caminho", questão 196 do Questionário Semântico Lexical (QSL) do Projeto Atlas Linguístico do Brasil (Projeto ALiB), vinculada à área semântica vida urbana. Os dados foram recolhidos de entrevistas realizadas em 24 localidades com 108 informantes do seguinte perfil: faixa etária I ( 18 a 30 anos) e faixa etária II ( 50 a 65 anos), sexos masculino e feminino, com ensino fundamental e superior, nas capitais, e ensino fundamental (interior). Os dados foram divididos entre três grupos: (a) denominações específicas do conceito em questão: calçada e passeio; (b) denominações genéricas: passarela, beirada e lateral (c) denominações de outros conceitos: acostamento.
\end{abstract}

Palavras-chave: variação lexical; região Centro-Oeste; Projeto ALiB.

\section{Nombres para la "acera" en el Centro-Oeste brasileño: un estudio geolingüístico}

\section{Resumen}

Este trabajo analiza los aspectos relacionados a la interpenetración del habla rural y urbano en la norma léxica de los habitantes del Centro-Oeste brasileño, buscando identificar interferencias de aspectos extralingüísticos y locales en la forma de nombrar un mismo elemento de la realidad. Fueron analizados seis unidades léxicas dadas como respuestas para el siguiente concepto:"En la ciudad, los automóviles recorren en el centro de la calle y las personas en los dos lados, en un camino con losas o ladrillos. Cómo se llama este camino", pregunta 196 del Cuestionário Semántico Léxico (QSL) del Proyecto Atlas Lingüístico de Brasil (Proyecto ALiB), vinculada al área semántica vida urbana. Los datos fueron recolectados de las encuestas realizadas en 24 localidades con 108 informantes del siguiente perfil: grupo etario I (18-30 años) y grupo etario II (50-65 años), géneros masculino y femenino, con escolaridad primaria y superior, en las capitales y en escolaridad primaria (interior). Los datos fueron divididos entre trés grupos: (a) denominaciones específicas del concepto en cuestión: "calçada e passeio"; (b) denominaciones genéricas:"passarela, beirada e lateral";(c) denominaciones de otros conceptos: "acostamento.

Palabras-clave: variación léxica; Centro-Oeste, Proyecto ALiB, acera. 


\section{Introdução}

A apurada observação do sistema lexical de uma língua fornece informações sobre variados aspectos da vida em sociedade, isso porque o léxico, à medida que nomeia elementos da realidade, revela peculiaridades da norma linguística de cada grupo de falantes.

Essa perspectiva é importante para o entendimento do fenômeno da variação linguística e para a compreensão dos fatores que motivam modos peculiares de fala, pois cada povo pode possuir uma maneira particular e específica de utilizar a língua, por interferências de fatores sociais e espaciais. No caso do falar dos habitantes da Região Centro-Oeste, é resultado do intenso contato entre povos indígenas, lusos e de brasileiros oriundos de diversas partes do Brasil. Em sua maioria, esse contingente populacional foi atraído, inicialmente, pela notícia do descobrimento de ouro na região e, posteriormente, pela possibilidade de desenvolvimento de atividades agrícolas e de criação de gado, dada a natureza do solo.

Partindo, pois, da premissa de que tanto traços socioculturais quanto características socioeconômicas refletem-se no léxico em uso por um grupo social, este trabalho tem como objetivo analisar aspectos relacionados à interpenetração do falar rural e urbano na norma lexical de habitantes da região Centro-Oeste, buscando identificar interferências de aspectos sociais (sexo, escolaridade, idade, profissão, entre outros) e espaciais na forma de nomear um mesmo elemento da realidade. Para tanto, foram examinadas sete unidades lexicais - calçada, passeio, passarela, beirada, acostamento, lateral e guarda-mão - fornecidas por 108 habitantes dos três estados da região CentroOeste, oriundos de localidades do interior e das capitais, como resposta para a questão 196 do Questionário Semântico-Lexical (QSL) do Projeto Atlas Linguístico do Brasil (Projeto $\mathrm{ALiB}$ ), área semântica vida urbana, que questiona o seguinte conceito: "na cidade, os automóveis andam no meio da rua e as pessoas nos dois lados, num caminho revestido de lajes ou ladrilhos. Como se chama este caminho".

Os dados aqui discutidos recuperam os resultados obtidos no estudo de Marins (2012) ${ }^{1}$ que investigaram aspectos da relação rural e urbano no léxico dos habitantes da região Centro-Oeste.

\section{Desenvolvimento socioeconômico e os movimentos migratórios no Brasil Central}

O povoamento da região Centro-Oeste tem estreita ligação com a hidrografia e com o exercício de certas atividades humanas. O processo de mineração do ouro no século XVIII, por exemplo, além de ter sido importante do ponto de vista econômico e cultural, muito contribuiu para a inserção dessa região no contexto nacional, haja vista que se tornou, assim como as demais regiões brasileiras, importante área de povoamento, sobretudo às margens dos grandes rios. De acordo com Innocencio (1988, p. 88), ao longo dos rios surgiram algumas cidades motivadas pelo descobrimento do ouro, como Goiás (inicialmente Vila Boa), Cuiabá, Vila Bela da Santíssima Trindade, entre outras.

\footnotetext{
${ }^{1}$ Dissertação de Mestrado O rural e o urbano: novos e velhos falares na região Centro-Oeste do Brasil, orientada pela Prof $f^{\text {a }}$ Dra. Aparecida Negri Isquerdo, defendida na UFMS, em 2012.
} 
Em virtude do povoamento humano dessa região, foram criadas fortificações militares, conforme salienta Duarte (1988, p. 244): "assim, às margens do Guaporé e Paraguai, surgiram os núcleos urbano-militares consolidando a ocupação da fronteira, Cáceres e Corumbá, em 1778 [...]". Em algumas dessas áreas, as constantes cheias dos rios do Pantanal exigem a retirada do gado para outras localidades, fator que também contribuiu para a expansão da pecuária no Estado de Mato Grosso (INNOCENCIO, 1988, p. 87).

O sul, o atual Mato Grosso do Sul, se fortaleceu com a pecuária, graças à vinda de criadores "procedentes da Bahia e de Minas Gerais que atingiram os campos naturais do planalto do sul de Mato Grosso [atual Mato Grosso do Sul], denominado por Campos de Vacarias" (DUARTE, 1988, p. 244). Já Goiás não apresentou fortes modificações econômicas nos séculos XIX e XX, conforme ocorreu em Mato Grosso, sobretudo na parte sul. O território goiano também resgatou a expansão da criação de gado e a fundação de Goiânia, bem como o surgimento de novos municípios impulsionaram a agricultura na década de 40 do século XX.

Na verdade, tanto a agricultura como a criação e o comércio do gado foram ainda mais intensificados na década de 40 do século XX, quando ainda havia grande disponibilidade de terras devolutas. A migração da população em direção à nova região "foi incentivada através de intensa propaganda oficial, que ficou conhecida como Marcha para o Oeste" (DUARTE, 1988, p. 16). O termo "Região Centro-Oeste" foi institucionalizado pelo governo federal, em 1941, quando o IBGE (Instituto Brasileiro de Geografia e Estatística) elaborou a primeira divisão regional do Brasil para fins estatísticos e didáticos. Segundo essa divisão, o Centro-Oeste passa a ser composto, inicialmente, pelos estados de Goiás e de Mato Grosso. Posteriormente, em 1960, agrega o Distrito Federal e, em 1977, o estado do Mato Grosso do Sul (em virtude da divisão do estado do Mato Grosso). Nesse contexto, o município de Campo Grande (sul do território mato-grossense) se torna um grande centro de comercialização de gado e local onde moravam importantes fazendeiros. Na verdade, em Campo Grande "se esboçou um movimento na história social de Mato Grosso que terá repercussões nas décadas de 60 a 70: o da emancipação da parte sul" (DUARTE, 1988, p. 246). E, dessa forma, em 1977, o sul do Mato Grosso torna-se o estado do Mato Grosso do Sul, em decorrência da divisão territorial, o terceiro estado a compor a região Centro-Oeste.

Consequentemente, essas questões de ordem histórica, política e econômica contribuíram para que, no Brasil Central, surgisse um rápido e progressivo crescimento da população urbana, como pode ser visualizado na Figura 1, a seguir. 


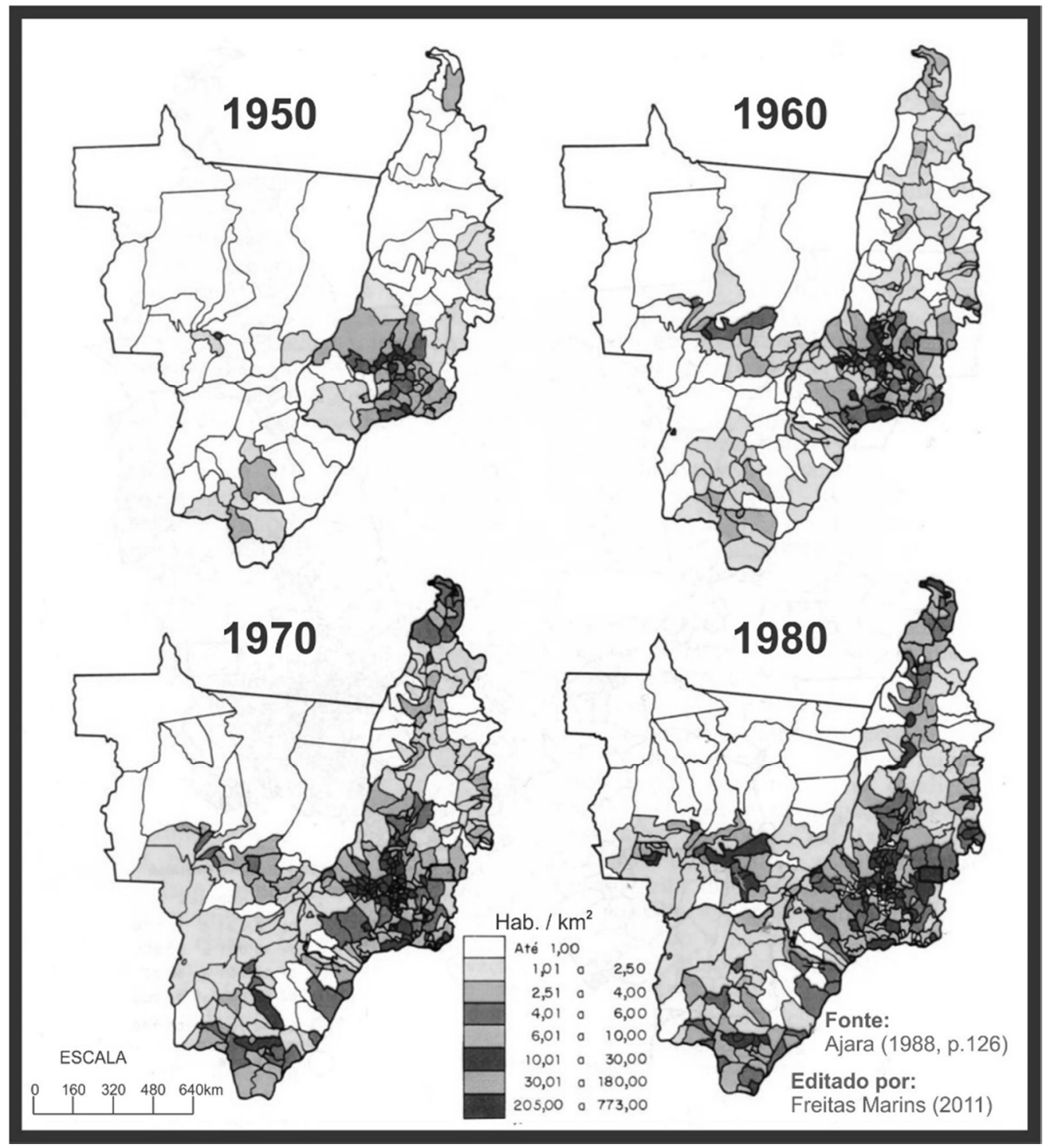

Figura 1. Crescimento da população urbana no Centro-Oeste, década de 1980

Fonte: Marins (2012, p. 51)

A comparação entre os mapas demonstra que, na década de 80, o território correspondente à Região Centro-Oeste recebeu um intenso fluxo de ocupação territorial, exceto o norte do estado de Mato Grosso, onde não se registraram alterações no índice de habitantes por metro quadrado, permanecendo, portanto, quase não povoado. Já o sul do estado do Mato Grosso do Sul e o centro do estado de Goiás, em especial nas localidades próximas à região do Distrito Federal (Brasília), concentram o maior índice de ocupação. No caso de Goiás, esse fenômeno pode ser justificado, segundo Ajara (1988, p. 128), pela criação de Brasília, pois "[...] a mudança da Capital Federal para o Planalto Central, seguida da implantação de um novo sistema viário a partir de Brasília, caracteriza-se pela intensificação do processo de ocupação regional".

Já o mapa da Figura 2 recupera dados apresentados pelo Censo 2010/IBGE ${ }^{2}$, no que se refere à população atual da região Centro-Oeste.

\footnotetext{
${ }^{2}$ Dados disponíveis em: <http://www.ibge.gov.br $>$.
} 


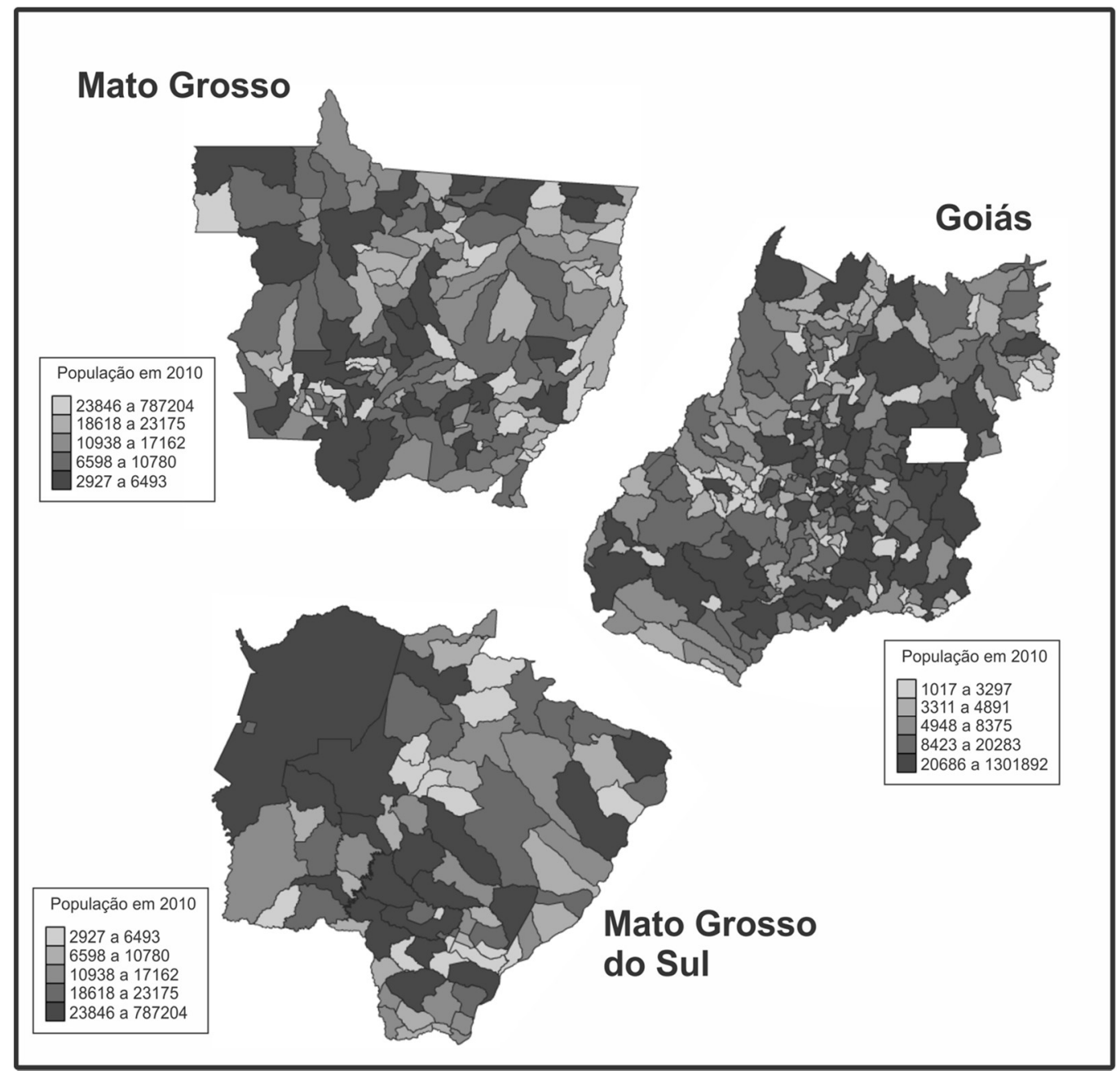

Figura 2. População atual da região Centro-Oeste

Fonte: Marins (2012, p. 51)

Observa-se pelo mapa da Figura 2 que, diferentemente dos resultados visualizados no mapa da Figura 1, o norte de Mato Grosso no período atual encontra-se povoado, assim como o nordeste de Mato Grosso do Sul e a parte central de Goiás. Esses dados confirmam o crescimento populacional da região Centro-Oeste que, até a década de 40 do século XX, era quase desabitada. Logo, é possível que também os hábitos, os costumes e a linguagem dessa população do Brasil Central estejam se alterando.

Em específico, no nível linguístico, entende-se que o léxico configura-se como uma importante ferramenta para a compreensão da transição sociocultural sofrida por uma sociedade. Sapir (1961, p. 51) salienta que o "léxico, ou seja, o assunto de uma língua, destina-se em qualquer época a funcionar como um conjunto de símbolos, referentes ao quadro cultural do grupo". Ao estudar uma palavra, identificam-se não somente questões estruturais do signo linguístico, mas, sobretudo, informações referentes à cultura, aos costumes, às crenças e aos conceitos vinculados por uma sociedade.

Essa atribuição de nomes à realidade é uma prática humana na história de qualquer língua. Em todas as épocas e culturas, o homem, mesmo concebendo a realidade de formas distintas, categorizou o universo de acordo com sua maneira de perceber o mundo 
e o nomeou por meio das palavras. E essa "arte de dar nomes às coisas é a arte rara, de difícil execução, pois exige que se olhe para o nome que cada coisa tem por natureza e se saiba exprimir, com letras e sílabas, sua ideia fundamental" (MARTINS, 2002, p. 50).

Na sequência, analisam-se as respostas obtidas para a questão 196 do Questionário Semântico-Lexical (QSL) do Projeto Atlas Linguístico do Brasil (Projeto ALiB), área semântica vida urbana, que busca designações para o seguinte conceito: "na cidade, os automóveis andam no meio da rua e as pessoas nos dois lados, num caminho revestido de lajes ou ladrilhos. Como se chama este caminho".

2. "Na cidade, os automóveis andam no meio da rua e as pessoas nos dois lados, num caminho revestido de lajes ou ladrilhos. Como se chama este caminho?": uma análise geossociolinguística

A coleta das respostas para a questão 196/QSL/ALiB resultou em sete itens lexicais: calçada, passeio, passarela, beirada, acostamento, lateral e guarda-mão (Tabela 1).

Tabela 1. Produtividade das denominações para "calçada" na Região Centro-Oeste

\begin{tabular}{l|c|c|c|c}
\hline \multicolumn{1}{c|}{ ITEM LEXICAL } & $\begin{array}{c}\text { CENTRO- } \\
\text { OESTE }\end{array}$ & $\begin{array}{c}\text { MATO } \\
\text { GROSSO }\end{array}$ & $\begin{array}{c}\text { MATO } \\
\text { GROSSO DO } \\
\text { SUL }\end{array}$ & GOIÁS \\
\hline Calçada & $81 \%$ & $80 \%$ & $84 \%$ & $79 \%$ \\
\hline Passeio & $7 \%$ & $4,2 \%$ & $3,1 \%$ & $12,5 \%$ \\
\hline Passarela & $4,7 \%$ & $8,5 \%$ & $3,1 \%$ & $2,08 \%$ \\
\hline Beirada & $3,9 \%$ & $4,2 \%$ & $3,1 \%$ & $4,1 \%$ \\
\hline Acostamento & $1,5 \%$ & - & $3,1 \%$ & $2,08 \%$ \\
\hline Lateral & $0,7 \%$ & - & $3,1 \%$ & - \\
\hline
\end{tabular}

Fonte: Banco de Dados do ALiB

\subsection{Dimensão diatópica}

Os dados da Tabela 1 evidenciam a alta produtividade da unidade lexical calçada para nomear o referente em causa, seguida de passeio, passarela e beirada. Já as respostas acostamento, lateral e guarda-mão tiveram menor vitalidade; essas duas últimas, por seu turno, foram ocorrências únicas. O Gráfico 1 detalha o exposto: 


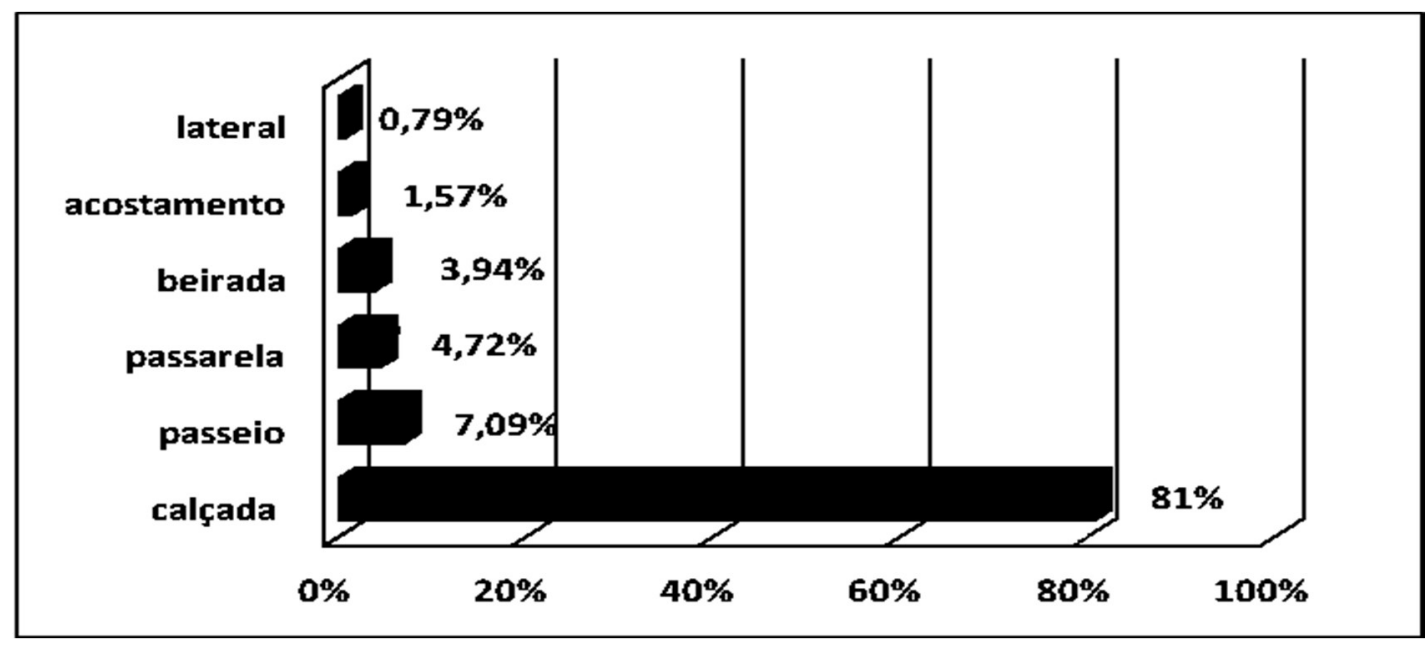

Gráfico 1. Produtividade das respostas para a pergunta 196/QSL na região Centro-Oeste

Fonte: Elaboração da autora a partir do banco de dados do ALiB

Conforme já assinalado, a unidade lexical calçada foi registrada em todas as cidades da rede de pontos do $\mathrm{ALiB}$ na região Centro-Oeste com alto índice de ocorrência. Já os itens lexicais passeio, passarela e beirada, embora documentados nos três estados pesquisados, alçaram índices bem menores de produtividade.

Nas capitais, passeio foi documentada apenas em Mato Grosso e em Mato Grosso do Sul, porém ao considerar o interior, esse resultado foi inverso, pois em Mato Grosso e em Mato Grosso do Sul não houve registro dessa unidade. Ao contrário, nas cidades do interior de Goiás, a unidade lexical passeio foi de uso recorrente em quase todas as cidades investigadas e pode indicar um traço de conservadorismo. Essa unidade lexical ainda é usual em Portugal, o que aponta para a fixação de uma herança linguística do colonizador português que ainda é mantida no léxico ativo dos habitantes do interior de Goiás.

Já a unidade lexical passarela foi registrada apenas em Campo Grande (capital do MS) e nas cidades do interior de Mato Grosso e de Goiás. Essa resposta foi obtida, em específico, exceto em Campo Grande, nas localidades situadas na divisa do estado de Mato Grosso com Goiás. A terceira resposta mais obtida na região Centro-Oeste foi beirada, item lexical documentado apenas no interior. É provável que esse termo de uso mais geral tenha sido mencionado em virtude da pouca familiaridade do informante com o referente em causa. Nas cidades de pequeno porte, nem sempre a calçada é um serviço disponível para a população, há um número elevado de ruas sem nenhuma pavimentação nas laterais. Essa unidade lexical - beirada - não nomeia, necessariamente, uma parte da calçada, o que pode justificar o uso desse nome de uso mais geral nas localidades mais interioranas. Essa mesma realidade pode ter motivado o uso da unidade lexical acostamento em Corumbá/MS e em Porangatu/GO. Esse nome, contemporaneamente, é atribuído às faixas laterais nas rodovias, logo, é possível que os entrevistados, por falta de familiaridade com o referente em questão, tenham feito uso de uma variante comum fora da área urbana. 


\subsection{Dimensão social}

Do ponto de vista diageracional, a única variante que apresentou variação significativa, considerando-se o perfil do informante, foi passeio, registrada apenas entre os informantes da faixa etária II. A Figura 3, a seguir, apresenta a distribuição espacial da unidade lexical calçada, bem como a distribuição diatópica para passeio na fala dos informantes da faixa etária XX da Região Centro-Oeste.

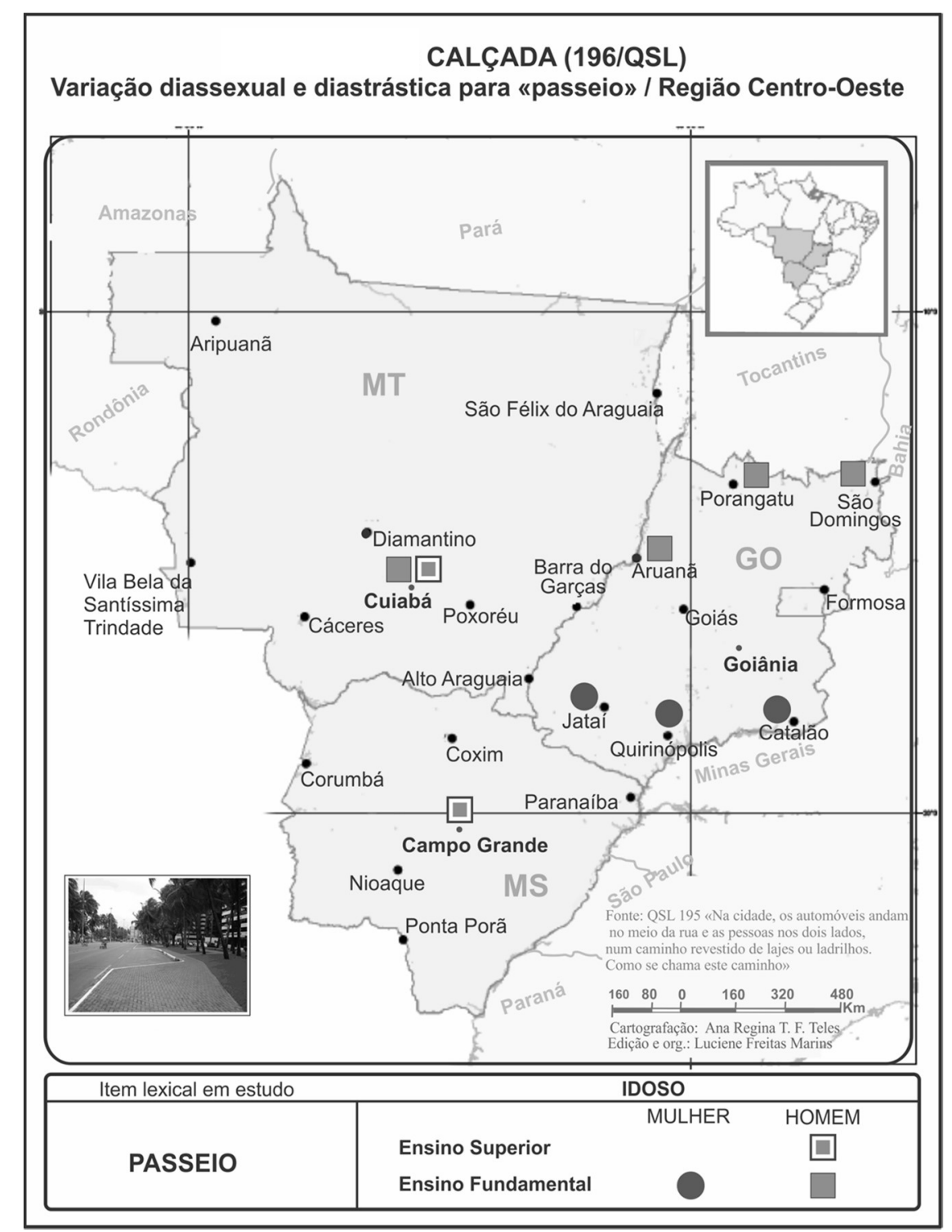

Figura 3. Variação diatópica e diassexual do item lexical "passeio" na região Centro-Oeste

Nota-se, pelos dados registrados na Figura 3, que a unidade léxica passeio foi documentada apenas entre os informantes da segunda faixa etária, com maior frequência entre os do sexo masculino, predominando no nível fundamental de escolaridade. Já entre os da faixa etária II, passeio foi registrado apenas entre as de baixa escolaridade. Nota-se ainda que, no interior de Goiás, esse item lexical foi documentado ao norte, apenas entre os informantes idosos do sexo masculino e, ao sul, apenas entre as informantes idosas. 
Enfim, no estudo das designações relacionadas à pergunta 196/QSL foram identificadas unidades lexicais de uso comum em todas as localidades e arcaísmos linguísticos evidenciados apenas na fala dos informantes da segunda faixa etária, como foi o caso do item lexical passeio. O registro dessa variante também foi importante por revelar a diferença entre a norma lexical do interior de Goiás e a do interior do Mato Grosso e de Mato Grosso do Sul.

\subsection{Análise léxico-semântica das respostas para a questão 196/QSL}

Para análise léxico-semântica, foram consideradas informações registradas em dicionários de diferentes fases da história da língua portuguesa: Bluteau (1712-1728), Silva (1813), Houaiss (2001) e Ferreira (2004). A partir dos traços semânticos apresentados pelos dicionários, as unidades léxicas foram distribuídas em três grupos: (a) denominações específicas do conceito em questão: calçada e passeio; (b) denominações genéricas: passarela, beirada e lateral (c) denominações de outros conceitos: acostamento. $\mathrm{O}$ quadro abaixo apresenta a dicionarização das unidades em questão:

\begin{tabular}{|c|c|c|c|c|}
\hline & & Unidade & & jicionários \\
\hline & Motivaçao & léxica & Antigos & Contemporâneos \\
\hline : & $\begin{array}{l}\text { Caminho } \\
\text { Calçado }\end{array}$ & Calçada & $\begin{array}{l}\text { "pancada com alça" } \\
\text { (SILVA, 1813); }\end{array}$ & $\begin{array}{l}\text { "caminho que é calçado ou } \\
\text { pavimentado, onde é possível a } \\
\text { circulação de pedestres" (HOUAISS, } \\
\text { 2001). }\end{array}$ \\
\hline 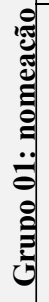 & $\begin{array}{l}\text { Lugar } \\
\text { elevado } \\
\text { onde se } \\
\text { passeia, } \\
\text { área ao ar } \\
\text { livre }\end{array}$ & Passeio & $\begin{array}{l}\text { "lugar do palseyo. Pa } \int \text { seyo } \\
\text { descoberto. Pafseyo } \\
\text { coberto" Bluteau (1712- } \\
\text { 1728) e "ato de passear } \\
\text { [...] lugar, ou jardim onde } \\
\text { se passeya" (SILVA, } \\
1813) ;\end{array}$ & $\begin{array}{l}\text { "caminho um pouco elevado que } \\
\text { ladeia as ruas junto às casas e se } \\
\text { destina ao trânsito dos pedestres; } \\
\text { calçada" (FERREIRA, 2004) }\end{array}$ \\
\hline : & $\begin{array}{l}\text { Lugar de } \\
\text { pedestre, } \\
\text { área } \\
\text { coberta. }\end{array}$ & Passarela & - & $\begin{array}{l}\text { ponte destinada a pedestres que estão } \\
\text { sobre ruas ou estradas (HOUAISS, } \\
\text { 2001; FERREIRA, 2004). }\end{array}$ \\
\hline : & $\begin{array}{l}\text { Parte } \\
\text { estreita }\end{array}$ & Beirada & $\begin{array}{l}\text { "borda, ribanceira, do mar, } \\
\text { do rio: margem, aba do } \\
\text { telhado, as telhas que sáem } \\
\text { fora do corpo do edifício" } \\
\text { (SILVA, 1813); }\end{array}$ & $\begin{array}{l}\text { "parte pequena ou estreita que se tira } \\
\text { de um todo, junto à sua borda" } \\
\text { (HOUAISS, 2001). }\end{array}$ \\
\hline 递 & $\begin{array}{l}\text { Parte } \\
\text { lateral }\end{array}$ & Lateral & $\begin{array}{l}\text { "que eftá em hum lado, ou } \\
\text { nos lados" (BLUTEAU, } \\
\text { 1712-1728) }\end{array}$ & $\begin{array}{l}\text { "aquilo que é relativo a lado" } \\
\text { (HOUAISS, 2001; FERREIRA, } \\
\text { 2004). }\end{array}$ \\
\hline 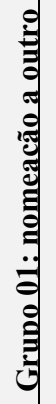 & $\begin{array}{l}\text { Parte da } \\
\quad \text { rua }\end{array}$ & Acostamento & $\begin{array}{l}\text { "Nome atribuído a uma } \\
\text { dada moradia" } \\
\text { (BLUTEAU, 1712-1728; } \\
\text { SILVA, 1813); }\end{array}$ & $\begin{array}{l}\text { Houaiss (2001), além de apresentar a } \\
\text { acepção "moradia ou ordenado que } \\
\text { os reis ou os fidalgos davam a seus } \\
\text { seguidores", acrescenta-lhe "área } \\
\text { junto ao meio-fio de uma rua ou à } \\
\text { margem de uma estrada, us. para } \\
\text { estacionar veículos" }\end{array}$ \\
\hline
\end{tabular}


Calçada e passeio compõem o grupo das unidades lexicais que nomeiam especificamente, na cidade, o caminho revestido de lajes ou ladrilhos onde as pessoas passeiam. O primeiro item está definido em Houaiss (2001) e em Ferreira (2004) como um caminho que é calçado ou pavimentado, onde é possível a circulação de pedestres. Ressaltam também ser um lugar geralmente mais elevado. Nota-se, portanto, que a definição da unidade lexical calçada contém os semas da pergunta. O mesmo ocorre com a forma passeio, que foi definida por Bluteau (1712-1728) como "lugar do palseyo. Palseyo descoberto. Palseyo coberto" e por Silva (1813) como "ato de passear. Modo de andar, e mover os passos [...] lugar, ou jardim onde passeya", acepção referendada pelos dicionários contemporâneos. Houaiss (2001), por exemplo, atribui-lhe a acepção de "caminho destinado à circulação de pedestres, quase sempre mais alto que a parte da rua em que trafegam os veículos; calçada" e Ferreira (2004) o define como "caminho um pouco elevado que ladeia as ruas junto às casas e se destina ao trânsito dos pedestres; calçada". O uso do item lexical passeio evidencia um traço de conservadorismo linguístico no vocabulário dos informantes idosos do interior de Goiás e das capitais mato-grossense e sul-mato-grossense.

Os itens lexicais passarela, beirada e lateral nomeiam genericamente ou por expansão de sentido os caminhos destinados a pedestres nas laterais da rua. Passarela, por exemplo, está definida nos dicionários contemporâneos na acepção de ponte destinada a pedestres que estão sobre ruas ou estradas. É possível que o uso dessa variante pelos entrevistados para nomear o conceito em causa tenha sido motivado pela presença do sema "pedestre" na definição da palavra. Já beirada em Silva (1813) está definida como "borda, ribanceira, do mar, do rio: margem, aba do telhado", enquanto Houaiss (2011) atribui-lhe a acepção de "parte pequena ou estreita que se tira de um todo, junto à sua borda" e Ferreira (2004) confere-lhe a acepção de "beira, margem, borda". Nota-se, assim, que as acepções registradas pelos lexicógrafos têm sentido genérico. Dessa forma, as jovens de Aripuanã (MT) e Porangatu (GO) e os idosos de Alto Araguaia (MT), Aruanã (GO) e Corumbá (MS) podem ter nomeado o referente em causa de beirada como forma de dar nome àquilo que fica na beira ou beirada da rua. A mesma motivação genérica pode ter ocorrido com o registro da variante lateral, mencionada pelo idoso de Corumbá (MS), forma definida por Bluteau (1712-1728) como "que eftá em hum lado, ou nos lados" e por Silva (1813) como "algo que é do lado". Houaiss (2001) e Ferreira (2004) definem a forma em causa como aquilo que é relativo a lado. Logo, o uso de passarela foi motivado pelos semas "lugar destinado a pedestres", sem levar em consideração a localização do caminho destinado ao tráfego de pessoas (na lateral ou em cima da rua); já os usos de beirada e lateral são nomeações mais genéricas voltadas para localização espacial desse caminho, no caso, os cantos da rua.

O mesmo ocorreu com o registro da unidade léxica acostamento que também sofreu alteração de sentido ao longo dos anos, passando a nomear contemporaneamente outro referente, no entanto, mais ligado aos semas presentes na questão 196/QSL. Bluteau (1712-1728) e Silva (1813) definem acostamento como o nome atribuído a uma dada moradia, enquanto Houaiss (2001), além de apresentar a acepção "moradia ou ordenado que os reis ou os fidalgos davam a seus seguidores", acrescenta-lhe "área junto ao meiofío de uma rua ou à margem de uma estrada, us. para estacionar veículos", definição essa referendada por Ferreira (2004): "na superfície de uma rodovia, faixa contígua à direita da pista de rolamento, destinada à parada eventual de veículos, ao trânsito de pedestres e ao de veículos em caso de emergência". 
Observa-se ainda que nenhuma das obras consultadas registra a acepção que nomeia o referente buscado na questão 196/QSL. Provavelmente, essa unidade lexical, na vida contemporânea, esteja adquirindo um novo sentido, uma vez que até então a unidade léxica acostamento era utilizada para nomear uma dada moradia e atualmente dá nome à pista lateral das rodovias. É possível também que o uso desse item léxico tenha sido motivado pela associação entre a faixa contígua à direita da pista de rolamento, destinada à parada eventual de veículos com o caminho revestido de lajes ou ladrilhos onde as pessoas andam.

\section{Considerações finais}

A interação do homem com os seus semelhantes é inevitável, uma vez que esse contato, além de propiciar a troca de conhecimento sobre si e sobre o outro, influencia a maneira como o homem percebe, vê e compreende tudo aquilo que compõe seu universo. Dentre os níveis linguísticos, "o léxico [...] é que mais reflete o ambiente físico e social dos falantes. O léxico completo de uma língua pode se considerar, na verdade, como o complexo inventário de todas as ideias, interesses e ocupações que açambarcam a atenção da comunidade" (SAPIR, 1969, p. 45).

Ao considerar as conjunturas históricas, sociais e econômicas da Região CentroOeste, observa-se a intrínseca relação com o panorama linguístico. O Brasil Central foi a última área geográfica povoada pelo colonizador português a partir da primeira metade do século XVIII, quando a busca por ouro e por índios motivou a entrada das bandeiras nesse território; além de ser a última região, em termos de povoamento efetivo, a própria nomeação "Região Centro-Oeste" foi institucionalizada pelo Governo Federal apenas em 1941, quando o IBGE elaborou a primeira divisão regional do Brasil, o que garantiu uma transformação no panorama urbano, recebendo em algumas cidades processo de pavimentação.

Logo, essa região tão marcada por atividades agropastoris passa a receber novas configurações mais urbanizadas, o que possibilita o convívio de nomeações mais arcaicas (até mais genéricas) com as do mundo urbano. Dessa forma, no conjunto lexical aqui analisado, foi possível identificar uma espécie de transição sociocultural sofrida por um povo, ora conservando a herança linguística deixada pelo colonizador, ora inovando o sentido, em virtude das questões geográfica, históricas e econômicas.

As respostas obtidas para a questão 196 do QSL demonstram que apenas as formas calçada e passeio estão dicionarizadas no sentido mencionado pelos informantes. No caso, em especial na unidade léxica passeio, observou-se um traço de conservadorismo linguístico na fala dos habitantes das capitais de Mato Grosso e de Mato Grosso do Sul e nas cidades do interior de Goiás. Já o uso das unidades lexicais passarela, beirada, lateral e acostamento sofreu alteração de sentido. É possível que por falta de familiaridade com o referente em causa, os falantes tenham se valido de associações de sentido para nomear o conceito em causa.

Enfim, as variantes aqui examinadas permitiram o mapeamento de uma unidade léxica que está em via de desaparecimento, na acepção de "calçada". 


\section{REFERÊNCIAS}

AJARA, C. População. In: Fundação Instituto Brasileiro de Geografia e Estatística, Geografia do Brasil - Região Centro-Oeste. v. 1. Rio de Janeiro: IBGE, 1988. p. 123148.

BLUTEAU, R. Vocabulário Portuguez \& Latino. Coimbra: Colégio das Artes da Companhia de Jesus, 1712-1728. (Acervos on-line). Disponível em: $<$ http://www.ieb.usp.br/online/index.asp>. Acesso em: 03 ago. 2015.

COMITÊ NACIONAL DO PROJETO ALiB. Atlas Linguístico do Brasil: Questionário 2001. Londrina: EDUEL, 2001.

DUARTE, A. C. O Centro-Oeste na organização regional do Brasil. In: Fundação Instituto Brasileiro de Geografia e Estatística, Geografia do Brasil - Região CentroOeste. v. 1. Rio de Janeiro: IBGE, 1988. p. 15-20; 244-267.

FERREIRA, A. B. de H. Novo Dicionário Eletrônico Aurélio da Língua Portuguesa. 3. ed. Curitiba: Positivo, 2004. Versão 5.0.

HOUAISS, A. Dicionário Eletrônico Houaiss da Língua Portuguesa. Rio de Janeiro: Objetiva, 2001.

INNOCENCIO, N. R. Hidrografia. In: Fundação Instituto Brasileiro de Geografia e Estatística. Geografia do Brasil-Região Centro-Oeste. v. 1. Rio de Janeiro: IBGE, 1988. p. 73-90.

MARINS, L. G. F. O rural e o urbano: novos e velhos falares na região Centro-Oeste do Brasil. 2012. 310 f. Dissertação (Mestrado em Estudos de Linguagem) - Universidade Federal do Mato Grosso do Sul, Campo Grande, 2012.

MARTINS, M. S. C. Entre palavras e coisas. São Paulo: Editora da UNESP, 2002

SILVA, A. de M. Diccionário da Lingua Portugueza - Lisboa: Tipographia Lacéridina, Tomos I e II. 1813. Disponível em: <http://www.ieb.usp.br/online/index.asp>. Acesso em: 10 ago. 2015.

SAPIR, E. Linguística como ciência: ensaios. Rio de Janeiro: Livraria Acadêmica, 1961. (Coleção Filologia e Linguística).

. Linguística como Ciência. Tradução de Joaquim Mattoso Câmara Júnior. Rio de Janeiro: Livraria Acadêmica, 1969. p. 8-62.

Recebido em: 02/09/2016

Aprovado em: 20/01/2017 